\title{
The periodicity of sleep duration - an infradian rhythm in spontaneous living
}

This article was published in the following Dove Press journal:

Nature and Science of Sleep

17 January 2013

Number of times this article has been viewed

\section{Shi Ngar Wong \\ Mark Halaki \\ Chin Moi Chow}

Discipline of Exercise and Sport Science, University of Sydney, Sydney, NSW, Australia
Correspondence: Shi Ngar Wong Room K222, K Block, C42, University of Sydney, Sydney, NSW 2I4I, Australia

Tel +6I 425623643

Fax +6I 2 935| 9204

Email swon2824@uni.sydney.edu.au
Abstract: The sleep-wake cycle is a process not only dictated by homeostatic and circadian factors but also by social and environmental influences. Thus, the total sleep time partly reflects sleep need, which is integral to the dynamics of sleep loss recovery. This study explored the nature of the observed oscillations in total sleep time in healthy adults under spontaneous living conditions. Actigraph-measured sleep data for 13 healthy young male adults were collected over 14 consecutive days and analyzed for habitual sleep duration. The total sleep time periodicity was modeled using the cosinor method for each individual across the 14 days. The findings confirm the existence of periodicity in habitual sleep duration as there were clear periodic patterns in the majority of the participants. Although exclusive to each individual, the observed oscillations may be a resultant response of homeostatic sleep need, circadian timing, and/or social and environmental influences. These findings instigate further indepth studies into the periodicity of sleep duration in healthy individuals to provide a better understanding of sleep need in short versus long sleepers, in predicting work performance, and reducing sleepiness-related accidents following shift work, and how this periodicity may impact sleep treatment outcome in clinical populations.

Keywords: sleep regulation, homeostasis, habitual sleep, spontaneous living, healthy males

\section{Introduction}

The sleep-wake cycle is closely linked to the processes of S and C., ${ }^{1,2}$ Process $\mathrm{S}$ maintains sleep homeostasis; during the wake period, sleep pressure builds up which dissipates during sleep. In contrast, the circadian process $\mathrm{C}$ defines the sleep-wake boundary based on physiological and environmental cues. ${ }^{1,2}$ Unlike process $\mathrm{S}$, process $\mathrm{C}$ occurs independently of prior sleep and waking and is hypothesized to set an upper and lower threshold to process $\mathrm{S}$ according to the time of day, ${ }^{3}$ so that whenever these processes intersect, a sleep bout is initiated or terminated. ${ }^{4}$ Additionally, the sleep-wake process is controlled by cognitive influences, eg, making conscious decisions about bedtimes and wake times. ${ }^{5}$ Both the homeostatic and circadian processes of sleep-wake regulation have been investigated under various experimental protocols including sleep deprivation and forced desynchrony. ${ }^{6}$ Remarkably, sleep-deprived individuals are more likely to have a consolidated bout of recovery sleep at night than during the day. ${ }^{7}$ Slow-wave activity, a robust marker of the homeostatic process $\mathrm{S}$, is also lowered during nocturnal sleep after a daytime nap. ${ }^{8}$ These results give rise to evidence for process $\mathrm{S}$ and $\mathrm{C}$ and in turn help to better understand the timing and duration of sleep and wake, which may be useful, for instance, in predicting work performance and reducing sleepiness-related accidents following shift work. However, to the authors' knowledge, there has been no documentation on how daily sleep duration cycles under normal living conditions. submit your manuscript $\mid$ www.dovepress.com

Dovepress

http:dx.doi.org// 0.2147/NSS.S38116
Nature and Science of Sleep 2013:5 I-6

(C) 2013 Wong et al, publisher and licensee Dove Medical Press Ltd. This is an Open Access article which permits unrestricted noncommercial use, provided the original work is properly cited. 
Sleep homeostasis dictates that sleep duration is a function of prior wakefulness. Large epidemiological studies have shown that sleep is often delayed and prolonged on weekends compared to weekdays in adolescents and adults. ${ }^{9-11}$ Extended weekend sleep duration suggests compensation for sleep debt accumulated on weekdays. ${ }^{12}$ Indeed, even patients with chronic primary insomnia demonstrate a rebound in total sleep time (TST) following a single night of sleep deprivation. ${ }^{13}$ Hence, sleep rebound is a feature of sleep homeostasis. On the other hand, the delay in weekend sleep phase may result in later bedtimes due to work and/or social commitments followed by sleeping-in the next morning. This creates a positive feedback loop which perpetuates the cycle.

Biological processes in humans oscillate with varying period lengths. The sleep-wake cycle oscillates with periods of approximately 24-28 hours (circadian), the nonrapid eye movement sleep and rapid eye movement sleep cycle alternates with periods less than 24 hours (ultradian), while the menstrual cycle has a period length of about a month (infradian). ${ }^{14}$ Many of these rhythms have a genetic basis, but circadian rhythms can be entrained by zeitgebers in addition to being endogenous and controlled by a central oscillator located in the suprachiasmatic nuclei of the hypothalamus. ${ }^{14}$ Research into biological rhythms has practical implications for everyday life and for the understanding and treatment of various disorders. ${ }^{15}$

Given that the circadian timing of sleep and wake is impacted by sleep homeostasis and lifestyle influences, the periodicity of sleep duration is of interest. This study's aim was to investigate habitual sleep duration under spontaneous living in healthy young male adults. It was hypothesized that in normal living conditions, a periodicity exists for sleep duration. That is, longer TST will follow shorter TST and vice versa.

\section{Material and methods}

\section{Participants}

Sleep data for 13 healthy males aged 18-35 years, measured by actigraphy (ACT), were analyzed. Participants had body mass indexes (BMI) $<30 \mathrm{~kg} / \mathrm{m}^{2}$, were not on any regular medication, and did not have any self-reported past or current medical conditions of cardiovascular, metabolic, or renal diseases and orthopedic problems, and were without sleep complaints. They were also nonsmokers, nonshift workers, and had not travelled between different time zones in the last 2 weeks.

\section{ACT}

ACT is a reliable and validated method for estimating sleep in normal healthy adults by detecting movement with an in-built accelerometer. ${ }^{16}$ Nondominant wrist ACT
(Actiwatch-2; Philips Respironics, Murrysville, PA, USA) data were collected for 14 consecutive days as part of a screening procedure for a larger study. During this period, participants slept at home and were asked to adhere to their normal daily activities and sleep-wake schedules. They were also instructed to press an event marker on the ACT when going to bed and upon waking. ACT data were retrieved and analyzed with the Respironics Actiware software (Actiware 5.57; Philips Respironics). Each 30-second epoch from the data recorded was defined by the software algorithm as being asleep or awake using the standard default settings. ${ }^{17}$ ACT data were supplemented by concomitant completion of a standard sleep diary for the purpose of artifact rejection. ${ }^{16}$ From this, 24-hour TST that included daytime naps was obtained over the fortnight period. ACT was also used to monitor activity level during the daytime, defined as the time from waking in the morning until bedtime. Daytime activity count per 30 -second epoch was summed to obtain the total activity count per day.

\section{Data analyses}

On visual inspection, a regular cyclic pattern was observed. Therefore, the periodicity of the sleep cycles (TST, including naps for each 24 hours, noon to noon) was modeled using the cosinor method, ${ }^{18}$ previously used to evaluate rhythmic sleep data, ${ }^{19}$ to model the sleep cycles for each participant over 14 days:

$$
\text { Modeled TST }(\mathrm{t})=\mathrm{M}+\mathrm{A} \times \cos (2 \pi \times \omega \times \mathrm{t}+\phi)
$$

In the equation, $t$ represents time (measured in days), $M$ represents the mean level (termed mesor), A represents the amplitude of the function, $\omega$ represents the frequency (or period $^{-1}$ ), and $\phi$ represents the horizontal shift of the function (termed acrophase). The spectral density function (window of 512 samples) was calculated for each TST pattern with the offset removed. The frequency at which the largest peak in the spectra occurred was then used for $\omega$ in the cosinor analysis which optimized the fit using the least squares method. The fit of the model to the data was then evaluated by the normalized root mean square of the difference (error) between the two signals. Pearson's correlation and linear regression analyses were used to investigate relationships between variables. Student's paired $t$-tests were used to compare TST and the mesor in the model.

\section{Results}

The participants (mean age $25.1 \pm 5.0$ years) habitually went to bed at 00:55 \pm 1:21 hours and woke at 08:04 \pm 1:15 hours. 
On average, they slept $6.5 \pm 1.0$ hours per day and rarely or never napped.

The model fitted to each participant's TST cycles over the fortnight is presented in Figure 1. The correlation coefficients (r) were $\geq 0.59$ and the error in the fit was $\leq 30 \%$ for all participants (Table 1). The sleep cycles for the group show periodicity with a range of 2.3-17.7 days, with a cycle peak-to-trough amplitude range of 81-208 minutes.

The average TST and the mesor in the model were not significantly different $(\mathrm{t}[12]=0.044 ; P=0.97)$ with a high correlation between the two measures $(r=0.90$; $P<0.05)$. The cycling nature (period or frequency) of the
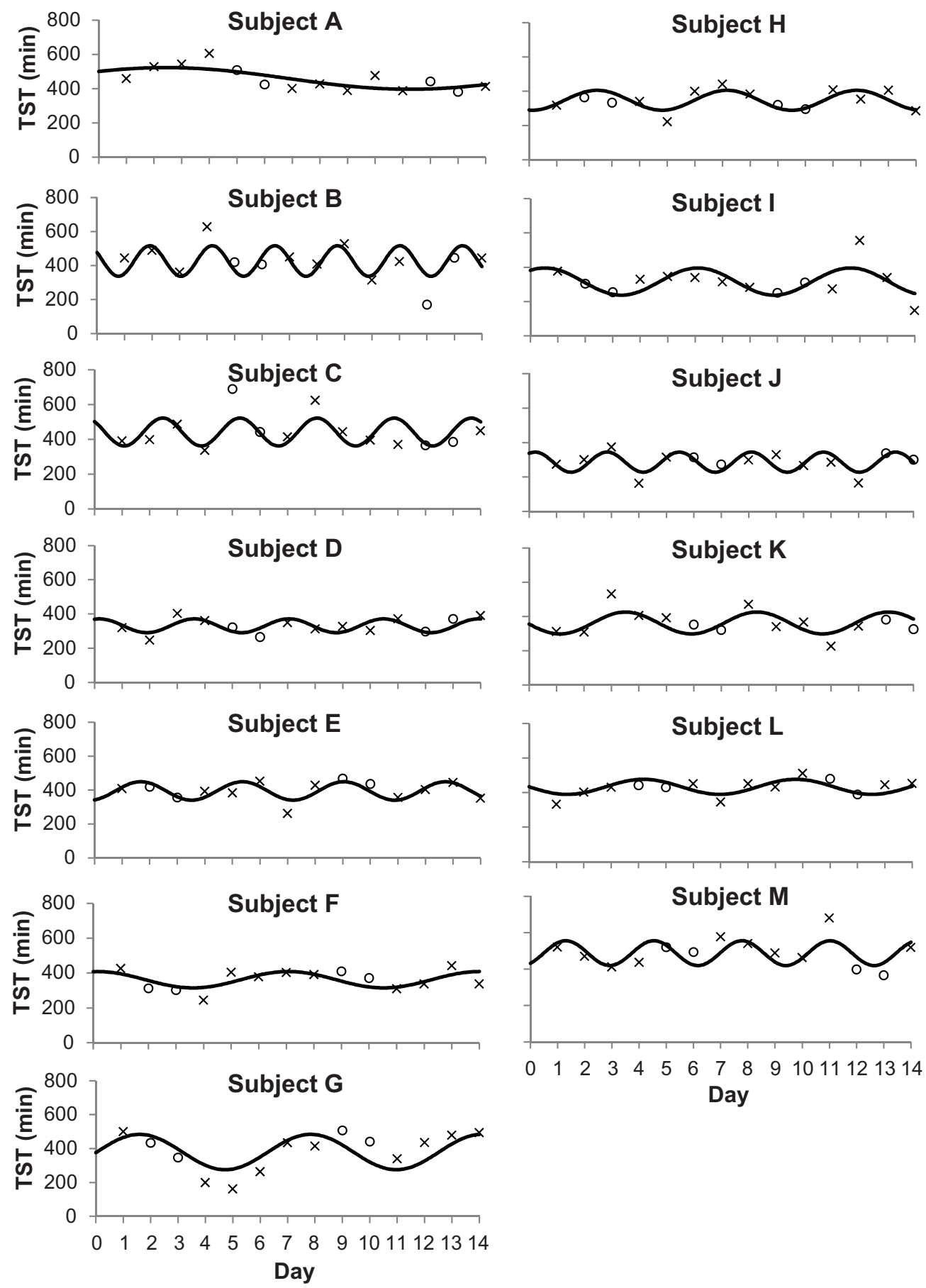

Figure I Habitual sleep duration (including, if any, daytime naps) for each participant across I4 consecutive days. Note: $X$ represents weekdays and $O$ represents weekends.

Abbreviations: min, minutes; TST, total sleep time. 
Table I Model parameters for each participant over a fortnight

\begin{tabular}{|c|c|c|c|c|c|c|}
\hline Subject & $\begin{array}{l}\text { Amplitude } \\
\text { (minutes) }\end{array}$ & $\begin{array}{l}\text { Frequency } \\
\left(\text { day }^{-1}\right)\end{array}$ & $\begin{array}{l}\text { Mesor } \\
\text { (minutes) }\end{array}$ & $\begin{array}{l}\text { Period } \\
\text { (day) }\end{array}$ & $\begin{array}{l}\text { RMS error } \\
\text { (\%) }\end{array}$ & $\begin{array}{l}P \text {-value for } \\
\text { amplitude }\end{array}$ \\
\hline A & 63 & 0.057 & 460 & 17.7 & 9.3 & $0.006^{a}$ \\
\hline B & 90 & 0.439 & 427 & 2.3 & 29.8 & $0.018^{a}$ \\
\hline C & 80 & 0.357 & 443 & 2.8 & 16.3 & 0.061 \\
\hline D & 40 & 0.291 & 331 & 3.4 & 10.7 & $0.029^{a}$ \\
\hline$E$ & 54 & 0.271 & 395 & 3.7 & 10.7 & $0.007^{a}$ \\
\hline $\mathrm{F}$ & 47 & 0.145 & 362 & 6.9 & 13.1 & $0.048^{\mathrm{a}}$ \\
\hline G & 104 & 0.160 & 379 & 6.2 & 28.9 & $0.013^{\mathrm{a}}$ \\
\hline $\mathrm{H}$ & 58 & 0.213 & 347 & 4.7 & 12.4 & $0.007^{a}$ \\
\hline I & 79 & 0.180 & 317 & 5.6 & 23.5 & $0.025^{\mathrm{a}}$ \\
\hline J & 59 & 0.381 & 286 & 2.6 & 18.7 & $0.014^{a}$ \\
\hline $\mathrm{K}$ & 64 & 0.209 & 361 & 4.8 & 15.6 & $0.033^{a}$ \\
\hline L & 44 & 0.180 & 433 & 5.6 & 8.7 & $0.026^{\mathrm{a}}$ \\
\hline M & 68 & 0.309 & 487 & 3.2 & 11.9 & $0.036^{\mathrm{a}}$ \\
\hline
\end{tabular}

Note: aSignificant amplitude as obtained from the cosinor analysis.

Abbreviation: RMS, root mean square.

sleep pattern was not related to any of the other variables ( $<<0.20 ; P>0.05)$. Participants with higher BMI tended to sleep earlier $(\mathrm{r}=-0.57 ; P<0.05)$ and longer $(\mathrm{r}=0.48$; $P<0.10)$. Those who slept earlier tended to sleep longer with significant correlations between bedtime and the offset $(\mathrm{r}=-0.55 ; P<0.10)$ and bedtime and TST $(\mathrm{r}=-0.64$; $P<0.05)$. These individuals also tended to wake up earlier $(\mathrm{r}=0.65 ; P<0.05)$.

\section{Discussion}

The finding of this study indicates that a periodicity exists for sleep duration in healthy males under spontaneous living. Sleep duration waxes and wanes with a periodicity that ranges between 2.3-17.7 days (Figure 1; Table 1). This periodicity will be discussed in terms of the possible mechanisms that may underlie the study observations.

The observed infradian periodicity of sleep duration may be a resultant response of process $\mathrm{S}$, ie, it appears that reduced TST for approximately $2-18$ days brings on sleep recovery. It is possible that variations in sleep amount are accompanied by compensatory adjustments on an ongoing basis in normal life, and that a homeostatic mechanism operates within the normal range of wake or sleep durations, as opposed to requiring a threshold amount of excess wake before a response is initiated. Previous authors have noted that interindividual variation in habitual sleep duration may be related to differences in sleep homeostatic responses such as a different rate of build-up or dissipation of sleep need. ${ }^{20}$ In fact, a study by Rusterholz et al revealed interindividual differences in the time constant of build-up of process S (range of 14.1-26.4 hours) following 40 hours of sustained wakefulness, and its decline (range of $1.2-2.9$ hours) during recovery sleep in healthy young males. ${ }^{21}$
Purportedly, individuals with slower accumulation and/or faster dissipation of sleep pressure have reduced sleep need, ${ }^{22}$ and vice versa, which may in turn define the periodicity of TST. Variations in daily sleep duration may also arise from differences in circadian processes,$^{20} \mathrm{eg}$, the timing of zeitgebers on a particular day or slight variations in the body clock. ${ }^{23}$ Moreover, there is emerging evidence to suggest that genetic factors may play a role in determining an individual's sleep architecture, as well as their response to sleep perturbation. ${ }^{24}$ Collectively, these effects may contribute to the large range of periodicity of sleep duration observed in the current study. Furthermore, the participants demonstrated cycle peak-totrough amplitudes of $>2$ hours, and therefore, in practice, an intervention (investigating sleep) that falls on the trough of a sleep duration cycle will maximize the sleep duration outcome. The fact that individuals differ in their periodicity of sleep duration suggests that baseline monitoring of such periodicity and testing participants on several nights (eg, nights falling on a peak or trough) will reflect a more representative outcome.

Notably, the participants in the current study habitually slept below the recommended $7-8$ hours. ${ }^{25}$ The relatively short TST accrued may be due to a delayed bedtime but convenient wake time in this sample, eg, voluntarily staying up late to socialize and/or use of electronic media, ${ }^{26}$ but waking up early to fulfill study or professional needs. Nevertheless, despite their short sleep (particularly subjects $\mathrm{D}, \mathrm{H}, \mathrm{I}$, and $\mathrm{J}$ who typically slept less than 6 hours per day), a periodicity exists. The observed periodicity was not uniquely different from those who had longer sleep duration, although there were insufficient data points for statistical comparisons. For instance, subject B had a periodicity of less than 3 days whereas subject A had a periodicity of 17.7 days. These subjects also had, on occasions, 
long sleep (eg, day four for both). Additionally, the model did not fit all the participants' sleep patterns well, specifically subject I. These points that lay outside the fitted curve may be accounted for by conscious decisions on bedtimes and rising times or possibly further unknown factors that modulate sleep and wake. Arguably, daytime behavior such as physical activity may impact on nighttime sleep. ${ }^{27}$ However, the current analysis of total daytime activity count (mean total activity count $286,047 \pm 73,832$ ) did not show an association with TST in the corresponding sleep periods, confirming previous observations. ${ }^{28}$ Whether short or long sleepers show differences in the infradian rhythm of sleep duration remains to be investigated. In contrast to earlier findings, ${ }^{9-12}$ average weekend sleep duration for the group was not higher than on weekdays, indicating that weekend sleep in this sample may be largely determined by intrinsic factors rather than by willed behavior. While the rhythmic model seems to fit the majority of the participants (ten of 13), there were three participants (subjects B, C, and J) for which the rhythmic model did not seem to be appropriate despite the cosinor function indicating an amplitude significantly different than zero $(P<0.05)$ for both subjects B and J. This could be due to them having an almost constant TST during the course of the study.

In the current study, it was found that higher BMI was positively correlated with sleep duration, thus supporting the results of others. ${ }^{29}$ The mechanisms behind weight gain and extended sleep duration remain unclear. Patel and $\mathrm{Hu}$, in their review paper, suggested that weight gain (particularly obesity) increases inflammation and release of cytokines which promote longer sleep. ${ }^{30}$ Nonetheless, the current results need to be interpreted with care because unlike the aforementioned study which compared extremely long sleepers with habitual TST of $\geq 10$ hours to optimal sleepers with habitual TST of 7 hours, ${ }^{29}$ the majority of the participants in the current study were short sleepers. Moreover, none of the participants were obese. An alternate explanation for longer TST with increased BMI is sleep apnea. ${ }^{31}$ Although this study did not screen for snoring, breathing pauses during sleep, and excessive daytime sleepiness, all of the participants reported no sleep problems. Later bedtime has been associated with increased BMI and may be linked to decreased sleep duration, ${ }^{32,33}$ but this was not supported by the current data. Earlier bedtimes were related to longer sleep durations, perhaps due to an increased opportunity for sleep. As expected, participants who had earlier bedtimes also had earlier waking times.

Several limitations of this study are noteworthy and need to be clarified in future research. The sample size was relatively small with the majority of the participants (ten of 13) being university male students, and hence the results may not be generalizable to other populations. However, enrolling male participants could be justified by the elimination of hormonal rhythms. Presently, the sleep duration data were collected across only 14 days. Future investigations with a large sample size and longer period of data collection would be needed to adequately model sleep duration periodicity. Whilst polysomnography provides more reliable data on sleep measures than ACT, it is time-consuming, costly, and labor intensive. Since social and environmental factors have direct influences on sleep timing, future research is required to reveal the characteristics of TST periodicity under regular sleep-wake patterns, supplemented by rigorous documentation of waking behavior, caffeine and alcohol consumption, illness, and factors governing choice of sleep duration.

\section{Conclusion}

In conclusion, periodicity in sleep duration exists in healthy male adults under conditions of spontaneous living. Future studies should aim to investigate the infradian periodicity of sleep duration in short versus long sleepers and how such periodicity may predict work performance, affect and reduce sleepiness-related accidents following shift work, and how it may impact treatment recovery in clinical populations.

\section{Disclosure}

The authors report no conflicts of interest in this work.

\section{References}

1. Borbely AA, Achermann P. Sleep homeostasis and models of sleep regulation. In: Kryger MH, Roth T, Dement WC, editors. Principles and Practice of Sleep Medicine. Philadelphia, PA: Elselvier Saunders; 2000:377-390.

2. Borbely AA. A two process model of sleep regulation. Hum Neurobiol. 1982;1(3):195-204.

3. Beersma DG, Gordijn MC. Circadian control of the sleep-wake cycle Physiol Behav. 2007;90(2-3):190-195.

4. Huber R, Tononi G. Sleep and waking across the lifespan. In: Berntson GG, Cacioppo JT, editors. Handbook of Neuroscience for the Behavioral Sciences, Volume One. Hoboken, NJ: John Wiley \& Sons; 2009 461-481.

5. Daan S, Beersma DG, Borbely AA. Timing of human sleep: recovery process gated by a circadian pacemaker. Am J Physiol. 1984;246(2 Pt 2): R161-R183.

6. Van Dongen HP, Dinges DF. Investigating the interaction between the homeostatic and circadian processes of sleep-wake regulation for the prediction of waking neurobehavioural performance. J Sleep Res. 2003;12(3):181-187.

7. Zee PC, Manthena P. The brain's master circadian clock: implications and opportunities for therapy of sleep disorders. Sleep Med Rev. 2007;11(1):59-70. 
8. Achermann P. The two-process model of sleep regulation revisited. Aviat Space Environ Med. 2004;75(Suppl 1):A37-A43.

9. Groeger JA, Zijlstra FR, Dijk DJ. Sleep quantity, sleep difficulties and their perceived consequences in a representative sample of some 2000 British adults. J Sleep Res. 2004;13(4):359-371.

10. Thorleifsdottir B, Bjornsson JK, Benediktsdottir B, Gislason T, Kristbjarnarson H. Sleep and sleep habits from childhood to young adulthood over a 10-year period. J Psychosom Res. 2002;53(1):529-537.

11. Basner M, Fomberstein KM, Razavi FM, et al. American time use survey: sleep time and its relationship to waking activities. Sleep. 2007;30(9):1085-1095.

12. Crowley SJ, Carskadon MA. Modifications to weekend recovery sleep delay circadian phase in older adolescents. Chronobiol Int. 2010; 27(7):1469-1492.

13. Harris J, Lack L, Wright H, Gradisar M, Brooks A. Intensive sleep retraining treatment for chronic primary insomnia: a preliminary investigation. J Sleep Res. 2007;16(3):276-284.

14. Haus E, Smolensky M. Biological clocks and shift work: circadian dysregulation and potential long-term effects. Cancer Causes Control. 2006;17(4):489-500.

15. Brody S. The genetics of circadian rhythms. Introduction. Adv Genet. 2011;74:1-12.

16. Littner M, Kushida CA, Anderson WM, et al. Practice parameters for the role of actigraphy in the study of sleep and circadian rhythms: an update for 2002. Sleep. 2003;26(3):337-341.

17. Respironics. Actiwatch Communication and Sleep Analysis Software with ActiReader: Actiware and Actiware CT Software and Hardware Manual. Murrysville, PA: Philips Respironics; 2009.

18. Nelson W, Tong YL, Lee JK, Halberg F. Methods for cosinorrhythmometry. Chronobiologia. 1979;6(4):305-323.

19. Buysse DJ, Monk TH, Carrier J, Begley A. Circadian patterns of sleep, sleepiness, and performance in older and younger adults. Sleep. 2005;28(11):1365-1376.

20. Klerman EB, Dijk DJ. Interindividual variation in sleep duration and its association with sleep debt in young adults. Sleep. 2005;28(10): $1253-1259$.
21. Rusterholz T, Durr R, Achermann P. Inter-individual differences in the dynamics of sleep homeostasis. Sleep. 2010;33(4):491-498.

22. Aeschbach D, Cajochen C, Landolt H, Borbely AA. Homeostatic sleep regulation in habitual short sleepers and long sleepers. Am J Physiol. 1996;270(1 Pt 2):R41-R53.

23. Waterhouse J, Fukuda Y, Morita T. Daily rhythms of the sleep-wake cycle. J Physiol Anthropol. 2012;31(1):5.

24. Tucker AM, Dinges DF, Van Dongen HP. Trait interindividual differences in the sleep physiology of healthy young adults. $J$ Sleep Res. 2007;16(2):170-180.

25. Steptoe A, Peacey V, Wardle J. Sleep duration and health in young adults. Arch Intern Med. 2006;166(16):1689-1692.

26. Asaoka S, Komada Y, Fukuda K, Sugiura T, Inoue Y, Yamazaki K. Exploring the daily activities associated with delayed bedtime of Japanese university students. Tohoku J Exp Med. 2010;221(3):245-249.

27. Youngstedt SD. Effects of exercise on sleep. Clin Sports Med. 2005; 24(2):355-365.

28. Youngstedt SD, Perlis ML, O'Brien PM, et al. No association of sleep with total daily physical activity in normal sleepers. Physiol Behav. 2003;78(3):395-401.

29. Adamkova V, Hubacek JA, Lanska V, et al. Association between duration of the sleep and body weight. Physiol Res. 2009;58(Suppl 1): S27-S31.

30. Patel SR, Hu FB. Short sleep duration and weight gain: a systematic review. Obesity (Silver Spring). 2008;16(3):643-653.

31. Brostrom A, Sunnergren O, Arestedt K, et al. Factors associated with undiagnosed obstructive sleep apnoea in hypertensive primary care patients. Scand J Prim Health Care. 2012;30(2):107-113.

32. Snell EK, Adam EK, Duncan GJ. Sleep and the body mass index and overweight status of children and adolescents. Child Dev. 2007;78(1):309-323.

33. Kathrotia RG, Rao PV, Paralikar SJ, Shah CJ, Oommen ER. Late sleeping affects sleep duration and body mass index in adolescents. Iran J Med Sci. 2010;35(1):57-60.
Nature and Science of Sleep

\section{Publish your work in this journal}

Nature and Science of Sleep is an international, peer-reviewed, open access journal covering all aspects of sleep science and sleep medicine, including the neurophysiology and functions of sleep, the genetics of sleep, sleep and society, biological rhythms, dreaming, sleep disorders and therapy, and strategies to optimize healthy sleep. The journal welcomes

\section{Dovepress}

original research, clinical \& epidemiological studies, reviews \& evaluations, case reports and extended reports. The manuscript management system is completely online and includes a very quick and fair peerreview system, which is all easy to use. Visit http://www.dovepress.com/ testimonials.php to read real quotes from published authors. 